\title{
Body building, travestismo e feminilidade
}

\section{Body building, transvestism and femininity}

\author{
Caio César Sousa Camargo PRÓCHNO \\ Maria José de Castro NASCIMENTO \\ Maria Lúcia Castilho ROMERA
}

\begin{abstract}
Resumo
Neste artigo, parte-se da ideia de corpo virtual, de sexualidade e das histórias do travestismo e transexualismo. Aborda-se a busca pelo feminino por alguns homens e também por mulheres. Para tanto, utiliza-se o conceito de body building, um fenômeno que começou no pós-guerra e vem se solidificando na atualidade devido ao desenvolvimento da ciência na área de cirurgia plástica e outros métodos de construção do corpo. Discute-se a inadequação do termo travestismo, uma vez que a caracterização do feminino nestes casos não está mais só nas vestes e sim, também no corpo. Por fim, fala-se a respeito da força que a feminilidade exerce sobre o ser humano e de um novo sujeito que surge nas sociedades atuais, desafiando conceitos teóricos e padrões culturais de gênero.
\end{abstract}

Unitermos: Body building. Feminilidade. Transexualismo. Travestismo.

\begin{abstract}
In this work, we address the search for the feminine side by some men and also by women, from the standpoint of the idea of the virtual body, of sexuality and the history of transvestism and transsexualism. To this end, we have used the concept of body-building, a phenomenon that began in the post-war period and which, today, is stronger than ever due to the development of science in plastic surgery and other body building methods. We discuss the inadequacy of the term transvestism since the characterization of what is feminine in these cases is not only in the wearing of clothes, but also in the body itself. Finally we question the power that femininity has over the human being and discuss the new individual that is emerging in society today, challenging theoretical concepts and cultural gender models.
\end{abstract}

Uniterms:Body building. Femininity. Transsexualism. Transvestism.

O estudo sobre o corpo humano enquanto virtualidade, entendida como tudo aquilo que tenha potencial para acontecer em qualquer tempo e espaço, é muito novo, instigante e curioso."Corpo, movimento, história, passado, presente, roupas, doenças, rituais, lutas, mortes, linguagem, escrita", o homem tem construído sua própria história a partir de seu corpo. Cicatrizes, tatuagens, escarificações, piercings, body building, body modification, body art, mutilações, implantes, transplantes, bioética e biocomércio configuram verdadeiras viagens ao centro do corpo, feitas com ele vivo e em funcionamento.

Dada a diversidade de áreas do conhecimento humano que abordam o tema, Greiner (2005) recomenda

\footnotetext{
$\boldsymbol{\nabla \nabla \nabla \nabla}$
}

1 Universidade Federal de Uberlândia, Instituto de Psicologia, Programa de Pós-Graduação. Av. Pará, 1720, Bloco 26, Sala 46, Campus Umuarama, 38400-902, Uberlândia, MG, Brasil. Correspondência para/Correspondence to: M.I.C. NASCIMENTO. E-mail: <majosecn@yahoo.com.br>. 
a importância de não se fixar somente em uma forma de pensamento ao estudar o corpo, pois, qualquer que seja a área escolhida - filosófica, antropológica, biológica, histórica, semiótica, estética, política, artística - haverá aspectos que ficarão em aberto. Assim, essa autora propõe estudos indisciplinares para se delinear uma visão sobre o corpo.

Góes (1999) fala da importância da apresentação corporal na atualidade como parte da construção do "eu", pois o homem não apenas possui um corpo, ele é esse corpo. Inicialmente, a ideia de corpo perfeito era ligada à moral, mas hoje é cada vez mais frequente o aparecimento do corpo como forma de comunicação social. Antigamente, um corpo forte era exclusividade de heróis; hoje, atividades como musculação e ginástica, além de dietas e cirurgias, levam a uma democratização dos corpos construídos.

O body building, conceito inovador que se refere ao corpo como objeto público em exposição, equiparável a obras de arte como pinturas, esculturas e fotografias, começou a ganhar força na época da Segunda Guerra Mundial. Anteriormente, corpos esculturais eram objetos de exposição apenas em atrações circenses. 0 corpo, que antes era fruto de preceitos religiosos, ou seja, austeridade e controle da aparência, hoje está a cargo da ciência, em detrimento de valores morais, e coloca em questão até os papéis sexuais na modernidade. Esteroides químicos, cirurgias plásticas, piercings e tatuagens ultrapassam os limites do natural humano e da diferenciação de gênero. Pessoas criam para si mesmas figuras andróginas, que não se enquadram às diferenciações naturais de gênero; a natureza é desafiada e a anatomia não é mais limite para criações. Não se trata de alterar uma imagem, a modificação é feita em corpos reais. Góes (1999) cita a artista plástica francesa Orlan, que desde 1990 vem se submetendo a várias cirurgias plásticas, às vezes com transmissão televisiva ao vivo, colocando em cheque o corpo/carne/imagem e transformando seu corpo em palco de debate público, artístico e científico no que diz respeito à questão da subjetividade.

O corpo está ultrapassado e requisitando tecnologias cada vez melhores para dar conta das demandas dos tempos atuais. Na época da Revolução Industrial, o corpo deveria ser dócil e ter força produtiva, mas hoje acontece o contrário. De produtores, os corpos passaram a ser consumidores, perderam sua singularidade e transformaram-se em bancos de dados genéticos por meio da bioinformática e biotecnologia. Se, nos séculos XV e $X V I$, roubavam-se corpos de túmulos para estudar anatomia, hoje existe o Projeto Genoma Humano, capaz de detectar doenças e controlar comportamentos individuais (Góes, 1999).

Esses são alguns aspectos relativos a estudos sobre o corpo, que revelam a amplitude do tema. Neste estudo o recorte foi a questão do travestismo, permeado pelo fenômeno de construção de corpo e da busca pela feminilidade.

\section{História da sexualidade humana}

Roussele (1983), baseado em documentos médicos, jurídicos e religiosos, mostra que a exaltação à homossexualidade na antiga Grécia era imperativa, porque a mulher não era reconhecida como parte daquelas sociedades. A paixão pelo corpo do outro, no entanto, interferia na ideia de estética do espírito livre, pois pregava-se a dissociação entre espírito e desejo. Esse modo de ser foi ratificado primeiro pelos médicos, devido ao culto ao corpo saudável dos homens, depois pela ciência e, por fim, pela organização política. Consequentemente, começou a haver uma educação do corpo da criança e do adolescente para se determinar os comportamentos sexuais do adulto. Surgiram os tabus da virgindade, castidade, solidão dos monges e práticas sexuais marginais legitimadas em ritos.

Aos poucos, a mulher surgiu no cenário social, deixando de ser mero corpo procriador e adquirindo o papel de mãe através de casamentos aparentes. Nos primeiros séculos da era cristã, toda a literatura biológica, costumes, cuidados, atividades civis e diversão levavam em conta a saúde dos corpos masculinos, e havia manuais sobre como prepará-los para a procriação; o corpo feminino foi esquecido pela ciência e mesmo pela cultura. Os recém-nascidos eram amarrados para serem moldados e se tornarem cidadãos robustos e saudáveis, tudo isso anunciando a repressão sexual que viria mais tarde.

As sociedades foram estabelecendo regras para o casamento, e eventos como estupro, incesto e adultério passaram a ser considerados crimes. Surgiram os concubinatos e as relações homossexuais começaram 
a ser legisladas. A virgindade, a fidelidade e a castidade foram legitimadas e novos ritos apareceram, como a "noite dos erros", "festim incestuoso", "ritos púnicos" e sacrifícios, para que alguns pagassem a Deus pelos pecados de todos.

O desejo sempre foi objeto de tentativa de domínio por séculos, diz Roussele (1983). As pessoas localizavam seus infortúnios no próprio corpo, que foi apenas controlado a custa de impotência e histeria. O mundo greco-romano conseguiu apenas resistir à tentação, e não acabar com o desejo. A História mostrou que o prazer que o corpo do outro pode proporcionar não traz paz ao espírito nem felicidade.

De um ponto de vista mais ideológico, Ussel (1980) diz que o exercício da sexualidade/prazer é inerente ao homem biológico e cultural; vários agentes, formas de ação e disseminação de costumes favoreceram, ao longo da História, classes sociais abastadas de forma seletiva. Essas questões, quando enfocadas pela ciência, passaram a determinar padrões de normalidade e anormalidade. No entanto, desde que sexo, amor, casamento e procriação andam juntos não se pode falar em atitudes pró ou antissexuais, afirma Ussel (1980), que postulou a existência de uma Síndrome Antissexual na sociedade capitalista, nascida no período da grande industrialização. A igreja nunca foi contra o ato sexual, afirma o autor; o foco dela foi sempre a libido, a pureza da alma e do corpo. A contenção sexual dos monges, no entanto, acabou sendo imposta a toda a população, especificamente na Idade Média, com o surgimento da burguesia e prenúncios da industrialização. Houve também um aumento populacional e a interiorização do desejo, seguida do seu silêncio, que levou a uma diversificação cultural de hábitos, moradias, utensílios domésticos, vestes, códigos morais, códigos de relacionamento com os outros e até consigo mesmo, fortalecimento do núcleo familiar e diferenciação de faixas etárias para o homem, com o aparecimento da criança e do adolescente. À pedagogia, diz o autor, ficou delegada a educação desses novos seres humanos, delimitando-se quais comportamentos sexuais thes seriam destinados, o que culminou em uma ética social para alguns, tornando essa educação uma forma de ascensão social. A educação sexual surgida no século XIX foi restrita a poucos jovens burgueses e priorizava informações sobre o fisiológico e/ou a vida animal reprodutiva, para que esses jovens não fossem corrompidos. Os comportamentos sexuais deveriam ser resguardados para a vida adulta, tudo isso em função do aumento populacional e diversificação de ocupações e papéis na sociedade.

Sobre a história da sexualidade, Foucault (1997) afirma que antes do século XVII ela era livre, expressando-se por meio de palavras e gestos, e acontecia sem escândalos. Já a partir daí, com o regime vitoriano e a sociedade capitalista, instalou-se a vergonha e a prudência médica. Os corpos deveriam ser fortes e reproduzir, garantindo força de trabalho. A sexualidade humana passou a ser discurso, podendo se manifestar em determinados lugares e ser comentada por determinadas pessoas. A "vontade de saber" passou a dar suporte e instrumento à sexualidade, exercida sob restrições. O prazer e o dizer sobre o sexo formularam interdições ou permissões, em um processo que levou à instauração e aparecimento de sexualidades polimorfas e à crescente vontade de saber, construindo a ciência da sexualidade. Como consequência, o sujeito buscou se conhecer e pesquisar fatores que interferem na sexualidade, incluindo as condições em que a atividade sexual figura no campo da moralidade.

O homem sempre se comportou baseado em valores estéticos. A moral nasceu da "estética da existência" presente na Antiguidade; códigos e maneiras de se conduzir foram estabelecidos e os primeiros sinais da interdição dos prazeres do corpo, ou seja, do comer, do beber, do dormir e do prazer sexual foram traçados. O indivíduo passou a ter que combater a si mesmo e a seus impulsos, procurando vencê-los, sem se deixar escravizar pelos prazeres.

Os antigos filósofos primeiro desenvolveram o conceito de liberdade e, depois, a temperança, virtudes que deveriam ser colocadas em prática no ato de conhecer-se; tratava-se de uma pretensa relação com a verdade. Instalou-se o que Foucault chamou de Prática do Prazer e da Virtude do modo Erótica. Nessa prática estavam circunscritas as relações de prazer que os gregos concebiam para homens e mulheres. Não existia homossexualidade como doença; a prática homoerótica era direcionada simplesmente pelo apetite sexual. Foucault questionou por que essa prática, antes tida como natural e comum, passou a ser da ordem da moral, e concluiu que os gregos começaram a se preocupar 
com a moral do jovem e com a formação de sua personalidade, o que mais tarde foi expandido às donzelas e sua moral.

Percebe-se que, aos poucos, a cultura foi moldando os comportamentos sexuais, e outra dimensão surgiu, questionando o que é o verdadeiro amor - se o carnal ou o de almas que se unem. A erótica de Platão atentou para as relações de amor como acesso às verdades através da renúncia aos prazeres, necessitando cada vez mais de elaborados mecanismos de controle dos impulsos, que culminaram no casamento. A questão fundamental humana passou do prazer para a pureza do desejo, mesmo antes do cristianismo.

Os prazeres sexuais eram um problema; e como usufruir deles e exercê-los foi algo que mudou o cenário da História, afirma Foucault. Passou-se a um modo de austeridade, com controle do corpo e da alma, e um respeito extremado por si mesmo, limitando a sexualidade à procriação e ao casamento, com acentuada valorização do conhecer-se. Havia a crença de que o homem é dotado de razão dada por Deus, e que somente a razão possibilita que o homem cuide de si mesmo.

Já em uma sociedade moldada, as práticas do conhecer-se resultaram em práticas de bom convívio social. A relação conjugal ficou fortalecida e obrigou o homem a se posicionar frente à mulher. Ao mesmo tempo, as pequenas cidades cresceram e sua organização política ficou complexa, com mais de um foco de poder e tensões. As regras e papéis sociais, antes claramente definidos, deram espaço para a soberania sobre si mesmo, inclusive para os governantes, que deveriam ter bons princípios e alma elevada. As atividades cívicas e sociais passaram a seguir as mesmas regras dos cuidados consigo mesmo.

Continuando a exposição de Foucault, com Galeno (médico grego que viveu por volta de 129 a 200 d.C.) o corpo reafirmou-se como local de doenças em contraposição aos prazeres de outrora. O ato sexual poderia curar ou trazer doenças, uma vitória da visão de que há benefícios na abstenção sexual, pois a sua prática denuncia a fragilidade do corpo humano. Fazia-se necessário afastar-se do corpo e não sentir desejo. Foi o prenúncio da moral sexual religiosa que, junto à política, fez crescer o estado. O lar e a família mantinham essa possibilidade e davam-Ihe suporte por meio do controle da sexualidade feminina, garantindo a descen- dência. Havia separação entre prazeres conjugais e extraconjugais, mas a vida do casal deveria continuar sendo harmoniosa.

Nesse momento da história, o amor pelos rapazes perdeu importância e a relação homossexual perdeu o sentido; os jovens passaram a ser protegidos de abusos sexuais. O mestre, por exemplo, deveria adotar agora uma postura paterna, pois o amor pelos rapazes também entrou para o rol dos cuidados e valorização do respeito consigo e para com os outros. $\mathrm{O}$ amor pelas mulheres jovens adquiriu importância, e o amor heterossexual, a castidade e a virgindade ganharam espaço. Os laços matrimoniais foram elevados à condição divina com o cristianismo, e o exercício da sexualidade heterossexual entrou definitivamente no campo da moralidade.

Assim, Foucault revela um intrincado cultural que, no ocidente, resultou na modelagem dos comportamentos humanos relativos à sexualidade. Pode-se perceber um direcionamento, uma pretensa vitória da heterossexualidade sobre a homossexualidade e da moral sobre o prazer sexual. Ao mesmo tempo, essa história revela que outras formas de exercício da sexualidade sempre existiram. Constata-se também que a nosografia patológica relativa à sexualidade humana surgiu somente no século XX, bem como a atenção à sexualidade feminina.

Flandrin (1988) fez trajetória semelhante à dos autores anteriormente citados quanto à história da sexualidade humana, porém sob um prisma diferenciado. Descobriu, nos documentos que analisou, o modo como o ser humano vem modelando e modificando sua subjetividade através daquilo que se convencionou chamar de amor. Primeiro este se configurou como um problema, pois era duplo: um direcionado ao corpo e o outro platônico. O laço afetivo amoroso entre casais heterossexuais só foi reconhecido tardiamente na História, invertendo a motivação dos casamentos que antes tinham finalidades de procriação e atenção às necessidades sociais e culturais. O corpo da mulher e sua subjetividade só foram reconhecidos no leito conjugal do século XX, talvez como pagamento a uma dívida de séculos de submissão e controle. O amor fraternal, paternal e filial surgiu com o sentido de família e cuidados com o filho varão, o que só foi possível mediante interiorização, que enriquece e transforma sentimentos. 
O amor maternal só veio surgir quase dois mil anos após Cristo, fazendo uma trajetória que veio do infanticídio à negligência com as crianças, passando por "enjeitamentos" e consequente mortalidade infantil. Flandrin (1988) afirma que a vida erótica e a manifestação da libido sob repressão sempre existiram nas diversas culturas, de formas mais ou menos intensas, e o desafio é saber em quê exatamente consiste a vida sexual dos povos.

Freud (1905/1969a), ao formular suas teorias sobre a sexualidade, mencionou uma inversão de objeto sexual manifestada por pessoas que se interessavam por outras do mesmo sexo. Em sua teoria da libido, existe o objeto sexual que atrai e o alvo sexual para o qual se direciona a pulsão. Freud atribuía ao evento fatores orgânicos neuronais inatos, como a degeneração, embora não acreditasse muito nesse fator, e lançou sua teoria da bissexualidade como algo natural no ser humano, pois a pulsão manifesta-se independentemente do objeto. Quanto à diferenciação entre homem e mulher, ele dizia que ocorre fisiologicamente na puberdade, mas o caráter da libido sexual em ambos é masculino. Teorizou o Complexo de Édipo na formação e conceituação da sexualidade normal e anormal. E, nessa mesma época, ao falar da sexualidade feminina, Freud (1932/1969b) deixou clara sua dificuldade em pensar sobre o assunto, uma vez que, segundo ele, seria impossível a psicologia desvendar o mistério da feminilidade porque esta é ligada à diferenciação ontogenética dos sexos e ao Complexo de Castração.

Partindo dessas ideias iniciais, discutem-se agora algumas questões que envolvem a sexualidade e a imagem do feminino nos dias atuais, uma imagem muito requisitada pela sociedade. Uma feminilidade expressa em corpos independentemente da definição de gênero, seja por meio do travestismo ou do transexualismo, seja por mulheres, todos, com corpos recriados pela medicina estética.

\section{A sexualidade que se traveste}

Dando ênfase ao feminino buscado por homens, os termos homossexualidade masculina, travestismo, transexualismo, castração ou drag queens são confusamente relacionados na literatura a aspectos psicológicos, sociais, culturais e biológicos. Alguns estudos são necessários para delimitar a especificidade do travestismo nos dias atuais. Parece que a feminilidade revela-se como fenômeno juntamente ao corpo construído e o corpo modificado, chamados respectivamente de body building e body modification, algo que ocorre em homens e mulheres.

Cardoso (2005) afirma que não há, atualmente, consistência nas categorias epistemológicas da descrição e definição dos gêneros, devido ao fato de a sexualidade ser um campo novo no conhecimento humano, e também por decorrência da abordagem multidisciplinar, o que dificulta o consenso. Assim, os fenômenos drags queens, transexualismo e travestismo são tratados sob a ótica dos fenômenos culturais. O termo "identidade de gênero", cunhado nos anos 1990, definia o ser como macho ou fêmea, masculino ou feminino, ou então andrógino, bissexual. Tais definições eram usadas frente à própria pessoa ou ligadas ao âmbito jurídico legal e consistiam em uma tentativa de reunir sexo, gênero e orientação sexual em um único conceito.

O autor diz que travestir-se é o mesmo que vestir-se com roupas e ornamentos do outro sexo, com caráter místico, festivo ou religioso, ou puramente como prazer sexual, e divide o travestismo em três categorias. A primeira delas inclui os ocasionais, que vivem como homens e podem ser casados e ter filhos. Os travestis com conflitos mais estáveis usam o travestismo mais frequentemente, fazem cirurgias plásticas, mas não querem se submeter a cirurgias transexuais. Já os do terceiro tipo são aqueles que não se reconhecem como pessoas de seu sexo anatômico; vivem há anos como pessoas do outro sexo e querem fazer (ou fazem) a cirurgia transgênero.

Saadeh (2004) aborda amplamente esse assunto e pontua que há necessidade de se restituir a humanidade nas pessoas portadoras de Transtornos de Gênero, o que não acontece muito no Brasil de hoje, onde ainda são tratados não apenas como objetos, mas como abjetos. São vistos como transgressores das normas e, mesmo aqui, onde o corpo travestido é aceito no carnaval e outras festas, passando uma ideia de aceitação pública, o preconceito é muito grande. O autor fala também sobre alguns aspectos mitológicos, históricos, transculturais e científicos que merecem destaque na área da transgenitalização e que são relevantes para a discussão aqui desenvolvida. 
Na mitologia grega, a deusa Afrodite simpatizava com almas femininas presas em corpos masculinos. Tirésias de Tebas, por castigo, foi transformado em mulher e novamente em homem, conhecendo os prazeres tanto de um quanto de outro. Sacerdotes na Turquia eram obrigados a se castrar e viviam como mulheres; isso ocorria em meio a uma festa consagrada como o "Dia do Sangue". Os gregos concebiam a deusa Hermafrodita, com formas femininas e masculinas. Alguns heróis gregos eram travestidos: Ceneu e Iffis eram do gênero feminino, e Himeneu, Céprops e Átamos eram do gênero masculino. Os heróis tinham também o direito de encontrar sua alma gêmea, restaurando, assim, um equilíbrio perdido na diferenciação de gênero inerente ao nascimento. Também segundo Saadeh (2004) existe uma lenda sobre um rei hindu que se transformou em mulher após banhar-se em um rio; o autor afirma ainda que a inquisição caçava e queimava bruxas que meleficamente se transformavam em homens para usufruírem da condição masculina.

Do ponto de vista histórico, segundo Saadeh (2004), no século I d.C. existiram os eunucos, que guardavam os palácios e aposentos femininos. Seguindo a linha de pesquisa histórica desse autor, alguns reis romanos teriam sido travestis, tais como Nero e Heliogábalo, e o Papa João VIII teria sido uma mulher. Trotula, médico e maior autoridade em ginecologia da Idade Média, travestia-se de mulher por ser proibido ao homem tratar o corpo das mulheres doentes. Na Renascença, o Rei Henrique III da França travestia-se e gostava de ser tratado como mulher. O termo "eonismo" vem de Chevalier d'Eon, travesti famoso e rival de Madame de Pompadour como amante de Luís XV.

Saadeh (2004) reforça a importância do fenômeno humano de alterações corporais ou de sua aparência social quanto ao gênero quando fala de tribos indígenas dos Estados Unidos, que deram origem ao termo bardash. Derivações deste termo em italiano, árabe e persa significam, respectivamente, escravo, michêe prostituto, e designam fenômenos semelhantes. Indivíduos de pequenas tribos na Sibéria, África, Brasil, Patagônia e Oceania também apresentam esses comportamentos. Há rituais religiosos de castração na Índia até os dias de hoje.

O autor afirma que os estudos científicos desses

242 fenômenos tiveram seu início com os alemães no século
XIX. Richard von Krafft-Ebing foi o primeiro, já no final do século, a publicar sobre o tema. No século XX, Magnus Hirschfeld publicou Die Transvestiten e foi o primeiro a usar o termo transexual, relacionando dez tipos de travestismo. Henry Havelock Ellis, na primeira metade do século passado, dedicou sua vida ao estudo, incentivo e explicitação de toda forma de atividade sexual. Foi a partir da década de 1920, no entanto, que surgiram as primeiras cirurgias para mudança de sexo dos hermafroditas. Alfred Kinsey, com sua famosa Escala Kinsey, revelou o grande número de pessoas que, na década de 1950, tinham tendências homoeróticas, e colocou a homossexualidade em um continuum de comportamentos sexuais aceitos.

O tema ganhou projeção nos Estados Unidos, em 1952, com um recruta das Forças Armadas que fez circular a notícia da primeira cirurgia transgênero no mundo. Somente nos anos 1960, no entanto, as questões transexuais tomaram aspecto científico, com Harry Benjamin, que estudou e estabeleceu uma escala para diagnóstico mais fidedigno e tratamento adequado, ficando bem diferenciado o homossexualismo do travestismo e do transexualismo. Seus estudos, ainda hoje, servem como linha mestra para as condutas quanto a transtornos de gênero.

Ainda do ponto de vista histórico, Saadeh informa que J. Money, por volta de 1950, proferiu a teoria psicossocial de gênero e identidade sexual, ligando o desenvolvimento mental ao físico; Robert Stoller reafirmou a separação entre o biológico e o psicológico nessas definições. Nos anos 1970, o transexualismo foi aceito como síndrome, figurando nos DSM-III e DSM-IV nas décadas de 1980 e 1990.

No Brasil, a primeira cirurgia foi realizada em 1971, com processo judicial contra o Dr. Farina por ser uma ilegalidade. A lei só foi regulamentada em 1979, com aprovação em nova resolução em 2002. O Hospital das Clínicas da Universidade Estadual de Campinas (Unicamp) possui um criterioso programa para realização gratuita de cirurgias transexuais. Em São José do Rio Preto, no estado de São Paulo, elas também acontecem. As cirurgias hoje são fatos reais, restando ainda as questões legais e jurídicas para o pós-operado.

Por fim, Saadeh (2004) afirma que a prevalência de transexuais masculinos para femininos, independentemente do país e da época, é de 3:1, embora outros 
autores afirmem que há incidência de transexualismo primário em número igual tanto para homens quanto para mulheres. Em casos de solicitação de cirurgia, o número de homens é sempre bem maior. Há cada vez mais estudos e técnicas cirúrgicas sofisticadas para transformar órgãos sexuais masculinos em neovaginas; hormônios são usados e a postura e reeducação de voz são trabalhadas para os transexualizados. Quanto mais jovem o indivíduo se submeter à cirurgia, melhores os resultados. Atualmente os casos são bem sucedidos, tanto biológica quanto emocionalmente.

Cardoso (2005) diz que tanto o DSM-IV quanto a CID-10 colocam o travestismo e o transexualismo como transtorno de identidade de gênero. Em 2001 havia uma prevalência de 1:2500 de transgêneros masculinos para femininos nos EUA, e hoje são realizadas de 1500 a 2 mil cirurgias por ano. São muitos os dados e estudos nessa área, devido à popularização das cirurgias, e é uma grande responsabilidade para as equipes interdisciplinares a preparação do indivíduo antes de realizá-las e o acompanhamento no pós-cirúrgico, devido a complicações socioemocionais e legais.

Há alguns estudos sobre o desenvolvimento cerebral do feto que merecem ser anotados, por ser outra forma de compreensão deste fenômeno. Após aplicação de escalas e pesquisas com 536 transexuais, Green e Young (2001) acharam, em seus estudos, que uma associação atípica do nível de hormônios sexuais, mais alterações na área dominante do cérebro de fetos, refletem na escolha de preferência sexual; de acordo com a teoria, alterações nas disposições de hormônios sexuais no período pré-natal dão origem ao desejo do indivíduo de transexualizar-se. Esses dados são condizentes com mulheres que foram expostas ao componente diethylstilbestrol (DES) que desenvolveram hiperplasia e virilidade congênita, e com a possibilidade de homens nascerem com Síndrome de Klinefelter.

Cahill (2005) também menciona estudos que comprovam diferenças na anatomia e funcionalidade cerebral de homens e de mulheres, afirmando que estas ocorrem na formação do feto e são inatas, frutos da evolução biológica e cultural humanas.

O panorama até agora apresentado leva a algumas constatações. Parece haver, ao longo da História, uma aparente busca pelo homem da imagem e da feminilidade em si, algo que tem sido expresso em roupas e gestos e buscado também pelas mulheres.

\section{O que se busca no feminino?}

Sant'Anna (2005), ao falar sobre "Horizontes do Corpo", faz um histórico sobre a modelagem dos corpos, em especial do feminino. A ideia do corpo como mercadoria, segundo a autora, remonta às origens da humanidade, mas atualmente os impactos da tecnologia e da comunicação levam essa possibilidade a ampliar-se enormemente. A visão do corpo como mercadoria teve início com apetrechos artificiais nas cortes europeias dos séculos XVI eXVII, época em que se usavam perucas, pintas artificiais, perfumes e maquiagens, culminando em uma imagem feminina recriada. Depois organizaram-se meios para"endireitar" o corpo feminino, com o uso de espartilhos que moldavam e davam forma, restando ao corpo a responsabilidade de governar a si mesmo. Hoje em dia, as academias também têm a função de modelar o corpo, sendo o molde agora a própria pele e os músculos. O contexto atual é de indústrias poderosas que aliam poder e saúde a bem-estar. O rejuvenescimento está veiculado em revistas e programas de televisão, dando à velhice feminina a ideia de algo antinatural. Tudo que se usa é com o objetivo de manter a aparência eternamente jovem. A visibilidade corporal é tanta que não existe mais a "alma", o corpo toma o significado de alma.

Esses aspectos reforçam a hipótese sobre o excesso de atenção que se dá ao corpo feminino, a uma feminilidade cultuada e cultivada por mulheres e homens com transtornos de gênero. A cultura atual do corpo parece querer eternizar flashes de sedução e feminilidade por meio de maquiagens, unhas e cílios postiços, batom, silicone, cirurgia plástica e adereços. Uma feminilidade de consumo que não tem mais a procriação como centro. Haverá um significado especial para o fenômeno?

Freud já indagava sobre o aspecto da feminilidade em corpos femininos. Hoje, com os adventos do body building, body modification e estudos sobre sexualidade, pode-se questionar o feminino em corpos tanto de homens quanto de mulheres. O que se busca? O que a ciência e as novas tecnologias de transformação do corpo humano estão anunciando ao mundo?

Butler (2003) é taxativa ao afirmar que há a emergência de um novo sujeito: uma nova subjetivação que ela chama de identidades queer, em uma nova con- 
cepção de gênero da contemporaneidade. Baseada em Freud e Foucault, diz que a heterossexualidade é compulsória, pois é fruto das relações de poder social e psíquico. A autora afirma ainda que a sexualidade deve ser vista a partir de um ponto de vista político, e nessas novas identidades há questões como casamento e estilos de vida, sobre as quais não se pode mais lançar o mesmo olhar de outrora. Ela questiona a binariedade sexual, alegando que ela é construída a partir da linguagem. O"cuidado de si"é prática de liberdade consciente e responsável. Um novo sujeito surge a partir da destruição da ideia de corpo e da reconstrução do próprio corpo, pois o ser constitui-se a partir do olhar e aceitação do outro. O mundo assiste cada vez mais à emergência e lutas de comunidades, que não podem mais ser negadas. São corpos resistentes, que constituem novas identidades de gênero. Não é mais a biologia que determina o gênero humano, e sim a cultura.

Quanto à imagem do feminino usada pelo travestismo, Almeida (1999), a despeito do imaginário de gênero, diz que ele é construído desde antes do nascimento do bebê, e coloca as diferenças entre transexuais e travestis. Os primeiros acreditam habitar um corpo errado, pois possuem corpo masculino com orientação sexual feminina. Querem parceiros heterossexuais, rejeitam a homossexualidade e, durante os atos sexuais, comportam-se como mulheres unicamente. Não olham e pouco tocam seus genitais; são fortes candidatos a cirurgias transgênero. Não convivem em guetos e não sentem atração por mulheres. Já os travestis têm comportamentos bissexuais e homossexuais, e usam adereços femininos para trabalhar na prostituição. Sentem atração por mulheres, às vezes, e durante o ato sexual assumem papéis masculinos e femininos. Vivem em guetos, onde são aceitos com mais facilidade.

Finaliza-se com os questionamentos de Silva (1999) sobre a identificação de gênero: ela é, afinal, determinada por cromossomos ou papéis sociais? São as roupas ou as atividades humanas que determinam quem é homem e quem é mulher? Serão os comportamentos e gestos corporais? Barba, músculos ou menstruação? Possuir pênis ou não? O autor afirma que o que fica bem claro é que essa definição é cobrada pela sociedade, estabelecendo normas e padrões ditados por uma classe social burguesa, capitalista, ocidental, patriarcal e heterossexual. A identidade de gênero é constituída ao mesmo tempo em que inúmeras descrições de sujeitos emergem, assim como intersubjetividades que surgem nas relações com os outros e conosco mesmos. O corpo, o gênero e o sexo são categorias frágeis frente à cultura e o psiquismo, promovendo conflitos identitários leves ou profundos.

\section{Considerações Finais}

Tentou-se abordar a feminilidade em corpos femininos e/ou masculinos nos dias atuais, juntamente aos grandes recursos tecnológicos que possibilitam a construção e a modificação do corpo, uma possibilidade que atinge algo tão específico para a humanidade: a sexualidade, a procriação e a manutenção da Espécie. O travestismo é algo que se anuncia desde os primórdios da História, mas somente há poucos anos pôde ser concretizado nos corpos, devido aos avanços tecnológicos da ciência. Talvez o termo travestismo não especifique aqueles indivíduos que, além de trocar as vestes típicas de seu gênero, submetem-se a cirurgias para acentuação e destaque de formas e aparências femininas. Nestes, a modificação fica também sob a pele e dentro do funcionamento do corpo, e não apenas nas vestes. Tratar-se-ia de um "neo" travestismo, uma vez que são pessoas que não se submetem a transgenitalização (no caso dos homens)? As mulheres que acentuam formas femininas seriam "neo" travestis? Poder-se-ia dizer que são simplesmente indivíduos que buscam recriar e eternizar a imagem do feminino jovem em seus corpos - paradoxalmente, um corpo feminino e sedutor, aparentemente pronto para a procriação?

Hoje as pessoas são mais consumidoras e menos produtoras de bens; estariam então mais livres para vivenciar a sexualidade? Houve um momento na História em que foi necessária uma diferenciação visual entre machos e fêmeas; hoje, essa diferenciação é desnecessária? O sexo por prazer é algo que atormenta a humanidade há anos em um jogo cultural de poder, constituição psíquica, constituição política e social, necessário ao desenvolvimento da humanidade. Hoje, seria a procriação algo secundário para os povos? A transgenitalização é um fato e está aí para ser pensada com seus aspectos psíquicos e culturais.

Além disso, evidencia-se a força da feminilidade. A mulher transgenitalizada já tem o feminino em seu 
corpo. Que falo é esse? Antes, Freud impactara-se frente à feminilidade das mulheres; o que diria desse feminino buscado por homens e mulheres da atualidade? Hoje, há a aceitação maior de casos considerados mais graves pela ciência, assim como a aprovação de cirurgias transgêneros, mas o travestismo ainda é cercado por preconceitos e certa indiferença por parte da ciência. Parece, no entanto, que o espaço cultural para esse novo sujeito realmente está existindo. Será que essa nova ordem se impõe para escancarar o desamparo a que os corpos foram sendo submetidos ao longo da História? Tratando-se de uma evolução de base ontogenética humana, os transexuais e travestis poderiam se beneficiar de ter ambas as identidades, masculina e feminina, tanto física quanto psiquicamente? Isso contribuiria para o desenvolvimento harmonioso das sociedades e felicidade humanas?

\section{Referências}

Almeida, S. J. A. (1999). Construindo o imaginário: a autorização para ser "mulher, heterossexual e ortodoxa". Revista Brasileira de Sexualidade Humana, 10 (1), 34-37.

Butler, J. (2003). Problemas de gênero: feminismo e subversão da Identidade. Rio de Janeiro: Civilização Brasileira.

Cahill, L. (2005). Ele e ela, a diferença anatômica dos cérebros masculino e feminino. Revista Cientific American-Brasil, 4 (37), 56-63

Cardoso, F. L. (2005). Inversão de gênero:"drag queens", travestismo e transexualismo. Psicologia:Reflexão e Crítica, $18(3), 421-30$.
Flandrin, J.-L. (1988). O sexo e o ocidente. Evolução das atitudes e dos comportamentos. São Paulo: Brasiliense.

Foucault, M. (1997). História da sexualidade. A vontade de saber (Vol. 1-3). Rio de Janeiro: Grall.

Freud, S. (1969a). Um caso de histeria, três ensaios sobre sexualidade e outros trabalhos (Vol. 7). Rio de Janeiro: Imago. (Originalmente publicado em 1905).

Freud, S. (1969b). O futuro de uma llusão, o mal-estar na civilização e outros trabalhos (Vol 21). Rio de Janeiro: Imago. (Originalmente publicado em 1932).

Góes, F. (1999). Do body building ao body modification: paraíso ou perdição. In N. Villaça, F. Góes \& F. Kosovski (Orgs.), Que corpoéesse? Novas perspectivas. Rio de Janeiro: Mauad.

Greiner, C. (2005). O corpo. São Paulo: Annablume.

Green, R., \& Yong, R. (2001). Hand preference, sexual preference and transsexualism. Archives of Sexual Behavio, 30 (6), 565-75.

Roussele, A. (1983). Pornéia: sexualidade e amor no mundo antigo. São Paulo: Brasiliense.

Saadeh, A. (2004). Transtorno de identidade sexual: um estudo psicopatológico de transexualismo masculino e feminino. Tese de doutorado não-publicada, Faculdade de Medicina, Universidade de São Paulo.

Sant'Anna, D. B. (2005) Horizontes do corpo. In M. L. Bueno \&A. L. Castro (Orgs.), Corpo território da cultura. São Paulo: AnnaBlume.

Silva, S. G. (1999). O Conflito identitário: sexo e gênero na constituição das Identidades. Rio de Janeiro. Revista Brasileira de Sexualidade Humana, 10 (1), 70-85.

Ussel, J. V. (1980). Repressão sexual. Rio de Janeiro: Campus.

Recebido em: 16/1/2007

Versão final reapresentada em: 25/4/2008

Aprovado em: 13/5/2008 
